\title{
Confined Electrochemical Behaviors of Single Platinum Nanoparticles Revealing Ultrahigh Density of Gas Molecules inside a Nanobubble
}

Wei Ma ( $\nabla$ weima@ecust.edu.cn)

East China University of Science and Technology https://orcid.org/0000-0003-0916-0150

Ze-Hui Sun

East China University of Science and Technology

Zhihao Gu

East China University of Science and Technology

Article

Keywords: electrocatalysis, electrochemistry, physicochemical properties, nanobubbles

Posted Date: June 1st, 2021

DOl: https://doi.org/10.21203/rs.3.rs-556728/v1

License: (c) (i) This work is licensed under a Creative Commons Attribution 4.0 International License.

Read Full License 


\section{Confined Electrochemical Behaviors of Single Platinum Nanoparticles Revealing Ultrahigh Density of Gas Molecules inside a Nanobubble}

Zehui Sun, Zhihao Gu, Wei Ma*

Understanding the basic physicochemical properties of gas molecules confined within nanobubbles is of fundamental importance for chemical and biological process. Here we successfully monitored the nanobubble-confined electrochemical behaviors of single platinum nanoparticles (PtNPs) at a carbon fiber ultramicroelectrode in $\mathrm{HClO}_{4}$ and $\mathrm{H}_{2} \mathrm{O}_{2}$ solution. Owing to the catalytic decomposition of $\mathrm{H}_{2} \mathrm{O}_{2}$, a single oxygen nanobubble formed on individual PtNPs to block the active surface of particle for proton reduction and suppress their stochastic motion, resulting in significantly distinguished current traces. Furthermore, the combination of theoretical calculation and high-resolution electrochemical measurement allowed the size of nanobubble and the oxygen gas density inside a single nanobubble to be quantified. And the ultrahigh oxygen density inside $\left(9286 \mathrm{~kg} / \mathrm{m}^{3}\right)$ was revealed, indicating gas molecules in a nanosized space existed with a high state of aggregation. Our approach sheds light on gas aggregation behaviors of nanoscale bubbles using single-entity electrochemical measurement.

[*] Z. Sun, Z. Gu, Prof. W. Ma

Key Laboratory for Advanced Materials and Feringa Nobel Prize Scientist Joint Research Center, School of Chemistry \& Molecular Engineering

East China University of Science and Technology

130 Meilong Road, Shanghai, 200237, P. R. China

E-mail: weima@ecust.edu.cn 
Formation, evolution and collapse of bubbles are common phenomena in nature, which are related to various important chemical and biological process ${ }^{1}$. Since Parker et al first proposed the existence of nanobubbles to explain the longrange attractive interaction between hydrophobic surfaces in water, ultrafine bubbles on surface has begun attracting great attention $^{2-4}$. The visualization of micro- or nano-scale bubbles formed at liquid-solid interfaces have been reported by using direct imaging such as atomic force microscopy, transmission electron microscopy (TEM) and other optical technologies ${ }^{5-9}$. Recently, the electrochemical measurement has also been utilized as a powerful method for studying the generation, nucleation and growth process of the nanobubble at the electrode surface ${ }^{10-12}$. A range of analytical measurements have confirmed nanobubble showing unique and quite different behaviors from macroscopic bubbles ${ }^{13}$. For example, the classical Epstein-Plesset theory predicts that micron or nanometer size bubbles will disappear within tens of microseconds or less. Nevertheless, ultrafine bubbles have been reported to last unusually long stability for days, weeks, and months ${ }^{14,15}$. Despite this remarkable progress, the basic physicochemical properties of gas molecules confined within single nanobubbles remain unclear ${ }^{16,17}$. A crucial issue for this problem is the gas density inside nanobubbles ${ }^{18-20}$. However, the direct experimental measurement of the gas density inside nanobubbles is very difficult because nanobubbles distribute heterogeneously on surfaces with ultralow coverage, and most spectroscopicbased techniques cannot collect signal from an individual nanobubble owing to the inferior spatial and time resolution of present measurement methods ${ }^{21,22}$.

Single-entity electrochemistry is an emerging technique that involves using Brownian motion to drive stochastic collision of individual freely diffusing entities at an ultramicroelectrode (UME), and measure the temporal changes in the current intensity of individual entities ${ }^{23-25}$. Single-entity electrochemical measurements have established themselves as a prominent tool for exploring the structural and kinetic features of individual entities that are hidden in ensemble-averaged measurements, including single nanoparticles (NPs), nanowires, cells, vesicles and proteins, and even single molecules and atoms ${ }^{26-28}$. With the development of new electrochemical instrument and methodology, ongoing efforts have been devoted to obtaining high-resolution electrochemical signals for understanding the motion behavior of individual NPs on the nanoscale ${ }^{29,30}$. Herein, we successfully monitored the nanobubble-confined electrochemical behaviors of single PtNPs in $\mathrm{HClO}_{4}$ and $\mathrm{H}_{2} \mathrm{O}_{2}$ solution. The formation of single oxygen nanobubble generated on individual PtNPs by the chemical decomposition of $\mathrm{H}_{2} \mathrm{O}_{2}$, meanwhile the cathodic current transients produced by proton reduction of single PtNPs in $\mathrm{HClO}_{4}$ solution when they collided with an UME surface (Fig. 1). Typically, comparing with only proton reduction of single PtNPs, significantly distinguished current trace with a lower current amplitude and a longer duration time was observed for single PtNPs in $\mathrm{HClO}_{4}$ and $\mathrm{H}_{2} \mathrm{O}_{2}$ solution due to the surface coverage and the confined motion of nanobubble to PtNPs. Based on the combination of theoretical calculation and high-resolution electrochemical measurement, our method can be used for quantifying the size of nanobubble and the ultrahigh density of the oxygen molecules existed in nanometer space on the PtNPs surface.

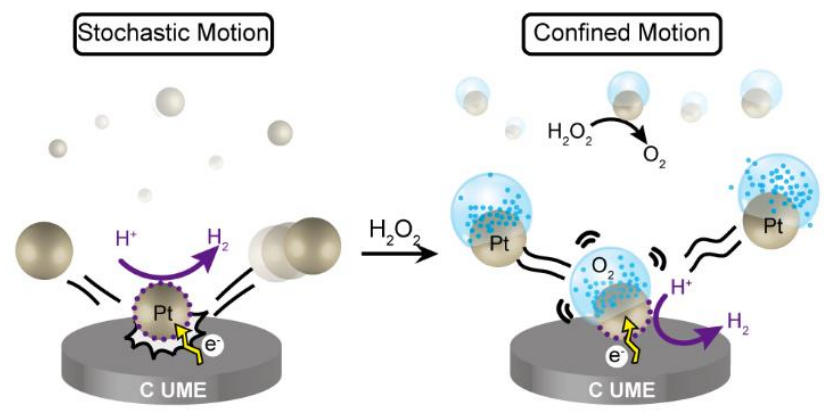

Fig. 1 The scheme illustrates the electrochemical behaviors of single PtNPs for the catalytic proton reduction during their collision at a $\mathrm{C}$ UME surface in $\mathrm{HClO}_{4}$ solution without and with $\mathrm{H}_{2} \mathrm{O}_{2}$.

\section{Results}

The nanobubble formation on individual PtNPs. In this study, we employed a carbon fiber UME with a radius of 3.5 $\mu \mathrm{m}$ (C UME, Supplementary Fig. 1) as an inert electrode surface to achieve the real-time electrochemical detection of single PtNPs collision event. Typically, small sized citratecapped PtNPs were prepared via citrate-mediated reduction. TEM image showed that the synthesized PtNPs possessed a narrow size distribution with an average size of $3.0 \pm 0.1 \mathrm{~nm}$, and the as-prepared particles were dispersed homogeneously (Supplementary Fig. 2). Briefly, a faradaic cathodic current transient easily occurred for proton reduction when diffusion-controlled PtNPs randomly collided at a C UME surface. The applied potential used in the acquisition of the electrochemical collision experiments was optimized to -500 $\mathrm{mV}$ vs. $\mathrm{Ag} / \mathrm{AgCl}$ wire for proton reduction in $\mathrm{HClO}_{4}$ and $\mathrm{H}_{2} \mathrm{O}_{2}$ solution (Supplementary Fig. 3). Before the addition of PtNPs, a smooth curve was observed in the amperometric current-time curve at $-500 \mathrm{mV}$ vs. $\mathrm{Ag} / \mathrm{AgCl}$ wire (Supplementary Fig. 4). After injection of PtNPs to a final concentration of $100 \mathrm{pM}$, significant current transients were observed for the catalytic reduction of proton in $50 \mathrm{mM}$ $\mathrm{HClO}_{4}$ solution containing $10 \mathrm{mM} \mathrm{NaClO}_{4}$ (Fig. 2a). In this case, a characteristic single peak with a duration time of 0.15 $\pm 0.01 \mathrm{~ms}$ and a current amplitude of $46.64 \pm 0.33 \mathrm{pA}$ corresponded to a single collision events of PtNPs (Fig. 2e). Then, $0.5 \mathrm{mM} \mathrm{H}_{2} \mathrm{O}_{2}$ was added into the above solution, a low current spike was further clearly observed (Fig. 2b); the current amplitude of spike signals decreased to $20.68 \pm 0.19$ $\mathrm{pA}$, while the duration tim increased to $0.19 \pm 0.01 \mathrm{~ms}$ (Fig. 2f). As well-known, $\mathrm{H}_{2} \mathrm{O}_{2}$ was catalytically decomposed by PtNPs to produce oxygen molecules, resulting in a large amount of supersaturated oxygen gas near the PtNPs in solution. When oxygen molecules around the PtNPs reached the critical concentration of bubble nucleation, single nanosized oxygen bubble was formed on the surface of individual PtNPs in bulk solution ${ }^{31}$. This current feature occurred because the generated oxygen nanobubble will partially block the reactive area of PtNPs and consequently impede the reduction reaction of proton, causing the 
decreased current amplitude. Meanwhile, the formed nanobubble decelerated the diffusion-controlled motion velocity of PtNPs in solution by increasing the hydrodynamic radius of bubble-particle agglomerations, thus leading to enlongate the duration time of current traces.

To verify this current change from the effect of nanobubble formation on the particle surface, we investigated electrochemical behaviors of single PtNPs after adding surfactant and defoaming agent into $50 \mathrm{mM} \mathrm{HClO}_{4}$ and $0.5 \mathrm{mM} \mathrm{H}_{2} \mathrm{O}_{2}$ solution. Symmetrical parabolic current traces were observed when poly(ethylene glycol) (PEG, 1.4 $\left.\mathrm{mg} \cdot \mathrm{mL}^{-1}\right)$ was added into the electrolyte solution, yielding a longer duration time of $0.23 \pm 0.01 \mathrm{~ms}$ and a lower current amplitude of $17.61 \pm 0.09 \mathrm{pA}$, respectively (Fig. 2c,g). It is well-known that surfactant molecules would favorably concentrate at the bubble/liquid interface after a nanobubble forms on the particle surface, thereby reducing the interfacial tension and also hindering gas molecules diffusion from the bubble into the solution ${ }^{32}$. We proposed that the nanobubble increasingly grew after adding PEG until the oxygen nanobubble stably formed on the surface of PtNPs; thus larger active reaction area of single PtNPs was covered and the current amplitude further decreased correspondingly. On the other hand, the nanobubble with a larger size can confine the motion of particle at a greater extend; that is, PtNPs was localized at/near electrode surface for longer time. However, a characteristic single peak appeared again when we added tributyl phosphate (TBP, $1 \mathrm{mg} \cdot \mathrm{mL}^{-1}$ ) as defoaming agent into the $50 \mathrm{mM} \mathrm{HClO}_{4}$ and $0.5 \mathrm{mM} \mathrm{H}_{2} \mathrm{O}_{2}$ solution, showing a duration time of $0.15 \pm 0.01 \mathrm{~ms}$ and a current amplitude of $44.50 \pm 0.26$ pA (Fig. 2d,h). In this case, current signals were close to the experimentally measured results in $50 \mathrm{mM}$ $\mathrm{HClO}_{4}$ solution without adding $\mathrm{H}_{2} \mathrm{O}_{2}$. The recovery of current amplitude and duration time can be ascribed to the fact that the presence of defoaming agent destroys the gasliquid interface of the nanobubble and the solution, leading to the nanobubble is unstable and rupture subsequently. All experimental results indicated that there was indeed the oxygen nanobubble formation on the surface of PtNPs generated by chemical decomposition of $\mathrm{H}_{2} \mathrm{O}_{2}$, which really confined the motion behavior of individual PtNPs dispersed in solution and reduced the catalytic activity of the PtNPs for proton reduction.
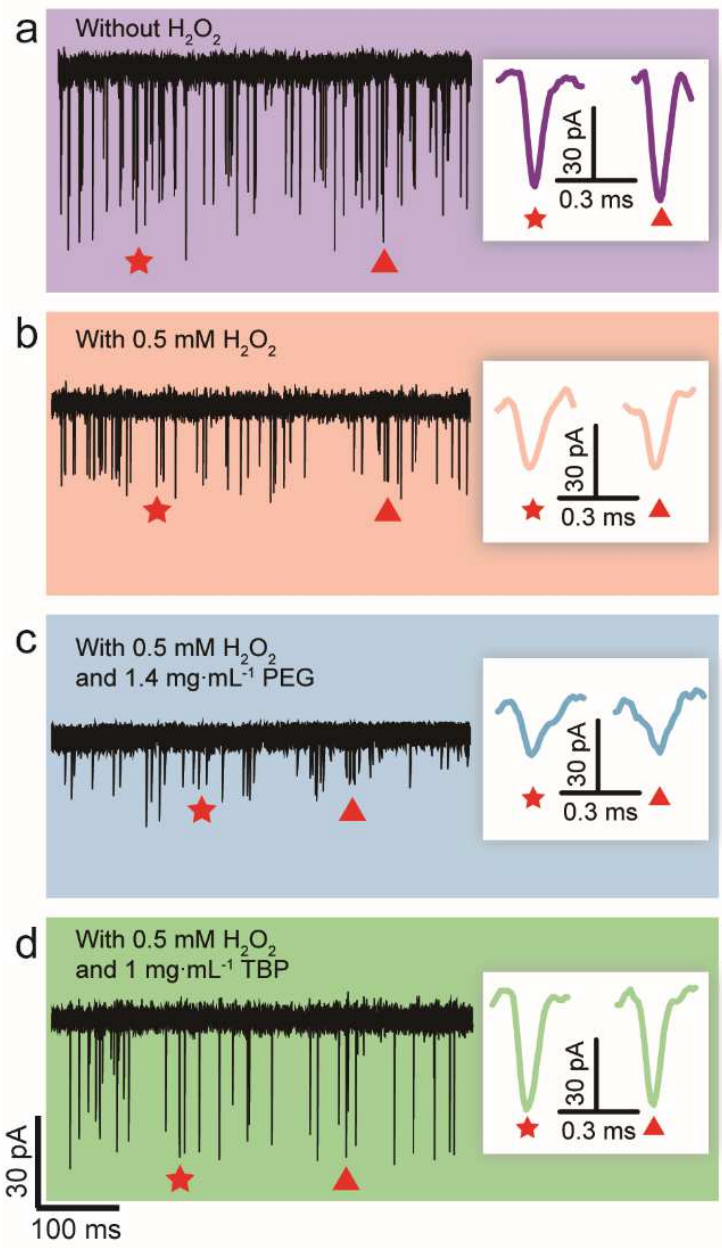
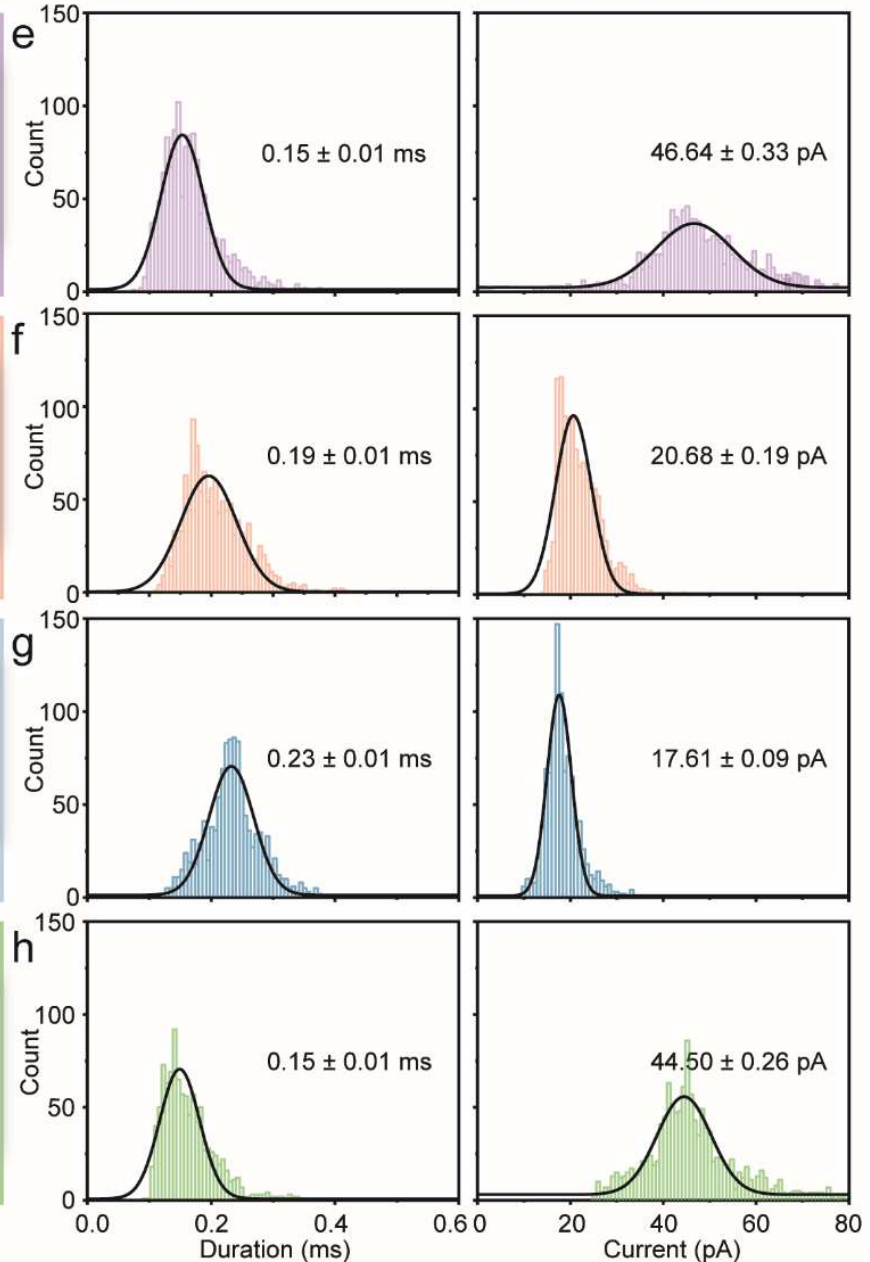

Fig. 2 Electrochemical behaviors of oxygen nanobubble formation and collapse process on individual PtNPs for the catalytic reduction of proton. Current responses of individual $3 \mathrm{~nm}$ PtNPs collisions at $-500 \mathrm{mV}$ vs. $\mathrm{Ag} / \mathrm{AgCl}$ at $\mathrm{C}$ UME (diameter $7 \mu \mathrm{m}$ ) in $50 \mathrm{mM} \mathrm{HClO}_{4}$ solution a without $\mathrm{H}_{2} \mathrm{O}_{2}$, b with $0.5 \mathrm{mM} \mathrm{H}_{2} \mathrm{O}_{2}$, c with $0.5 \mathrm{mM} \mathrm{H}_{2} \mathrm{O}_{2}$ and $\mathbf{d} 1.4 \mathrm{mg} \cdot \mathrm{mL}^{-1} \mathrm{PEG}$, and $0.5 \mathrm{mM} \mathrm{H}_{2} \mathrm{O}_{2}$ and $1 \mathrm{mg} \cdot \mathrm{mL}^{-1} \mathrm{TBP}$. Inset: Close-ups of the representative time-resolved current traces, corresponding to the spikes. e-h Histograms showing the distributions of the durations time and current amplitude of PtNPs. Black curves show Gaussian fits. The data were obtained from a large population of proton reduction events of individual PtNPs (more than 1000 events). 

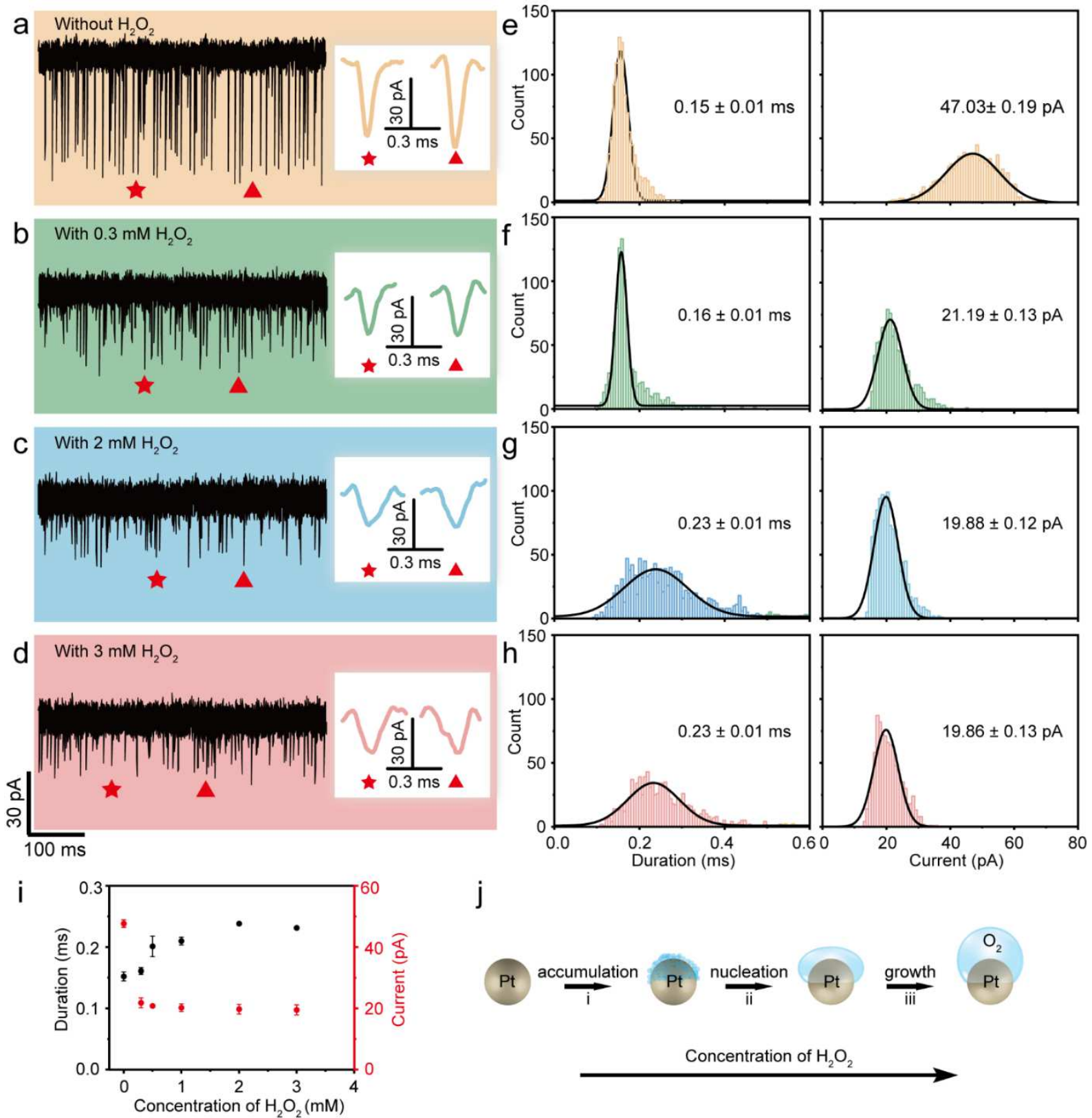

Fig. $3 \mathrm{H}_{2} \mathrm{O}_{2}$ concentration dependent electrocatalytic reduction behaviour of single PtNPs. Current responses of individual $3 \mathrm{~nm}$ PtNPs collsions at $-500 \mathrm{mV}$ vs. $\mathrm{Ag} / \mathrm{AgCl}$ at $\mathrm{C} \mathrm{UME} \mathrm{(diameter} 7 \mu \mathrm{m}$ ) in $50 \mathrm{mM} \mathrm{HClO}_{4}$ a without $\mathrm{H}_{2} \mathrm{O}_{2}$, b with $0.3 \mathrm{mM} \mathrm{H}_{2} \mathrm{O}_{2}$ (blue), c with $2 \mathrm{mM} \mathrm{H}_{2} \mathrm{O}_{2}$ (green), and d with $3 \mathrm{mM} \mathrm{H}_{2} \mathrm{O}_{2}$ (yellow). Inset: Close-ups of the representative time-resolved current traces, corresponding to the spikes. e-h Histograms showing the distributions of the durations time and current amplitude of PtNPs. Black curves show Gaussian fits. The data were obtained from a large population of proton reduction events of individual PtNPs (more than 1000 events). i Duration time and current amplitude of current traces as function of concentrations of $\mathrm{H}_{2} \mathrm{O}_{2}$. $\mathbf{j}$ The hypothetical growth process of oxygen nanobubble at individual PtNPs surface.

The properties of nanobubble on individual PtNPs.To further elucidate the properties of oxygen nanobubble on particle surface, we investigated the electrochemical collision behaviors of single PtNPs in $50 \mathrm{mM} \mathrm{HClO}_{4}$ solution containing different concentrations of $\mathrm{H}_{2} \mathrm{O}_{2}$ ranging from 0 to $3 \mathrm{mM}$. As expected, Fig. 3 displayed the $\mathrm{H}_{2} \mathrm{O}_{2}$ concentrations dependence of the maximum current, showing an initial linear decrease before reaching a constant value. A clear decreasing trend in current internsity was observed as the concentrations of $\mathrm{H}_{2} \mathrm{O}_{2}$ increased from 0 to
$2 \mathrm{mM}$ (Fig. 3a-c). This trend could be due to the generated oxygen nanobubble gradually growing as the concentration of $\mathrm{H}_{2} \mathrm{O}_{2}$ increased, resulting in larger active reaction area of single PtNPs was increasingly covered. Comparing with current spikes in the absence of $\mathrm{H}_{2} \mathrm{O}_{2}$, the current amplitude showed a more than half of the decay from $47.03 \pm 0.19 \mathrm{pA}$ to $19.88 \pm 0.12 \mathrm{pA}$ after adding $2 \mathrm{mM} \mathrm{H}_{2} \mathrm{O}_{2}$ into the $50 \mathrm{mM}$ $\mathrm{HClO}_{4}$ solution (Fig. 3e-g). This suggested almost 58\% active surface of PtNPs was covered by oxygen nanobubble in $2 \mathrm{mM} \mathrm{H}_{2} \mathrm{O}_{2}$ system. Correspondingly, the duration time 
of single PtNPs at the $\mathrm{C}$ UME gradually elongated to $0.23 \pm$ $0.01 \mathrm{~ms}$ as the concentration of $\mathrm{H}_{2} \mathrm{O}_{2}$ increased to $2 \mathrm{mM}$ (Fig. $3 \mathrm{~g}$ ). It is worthy note that the single peak in $0.3 \mathrm{mM} \mathrm{H}_{2} \mathrm{O}_{2}$ solution appeared with a duration time of $0.16 \pm 0.01 \mathrm{~ms}$ and a current amplitude of $21.19 \pm 0.13 \mathrm{pA}$ (Fig. 3f). This result occurred because oxygen gas accumulated to form an oxygen nanobuble of spherical cap on the NPs surface while the height of bubble was low, thus the confined effect to motion of PtNPs was negligible. At further increasing the concentration of $\mathrm{H}_{2} \mathrm{O}_{2}$ to $3 \mathrm{mM}$, current amplitude and the duration time are almost same with that in $2 \mathrm{mM} \mathrm{H}_{2} \mathrm{O}_{2}$ solution (Fig. 3h). We speculated that the integrated flux of $\mathrm{O}_{2}$ across the total nanobubble surface equals zero for the exposed Pt surface, and this bubble geometry represented a true steady state, as long as the concentration of $\mathrm{H}_{2} \mathrm{O}_{2}$ was more than $2 \mathrm{mM}$. Our results have shown that oxygen gas accumulated initially in an ultrathin film, and subsequently grew into nanobubbles of spherical cap with a large aspect ratio, and further grew with a higher rate in the vertical rather than the horizontal direction; Finally, the nanobubbles were in a dynamic equilibrium between bubble dissolution and supply of gas generated at the three-phase interface, suggesting that nanobubbles do not further grow (Fig. 3j).

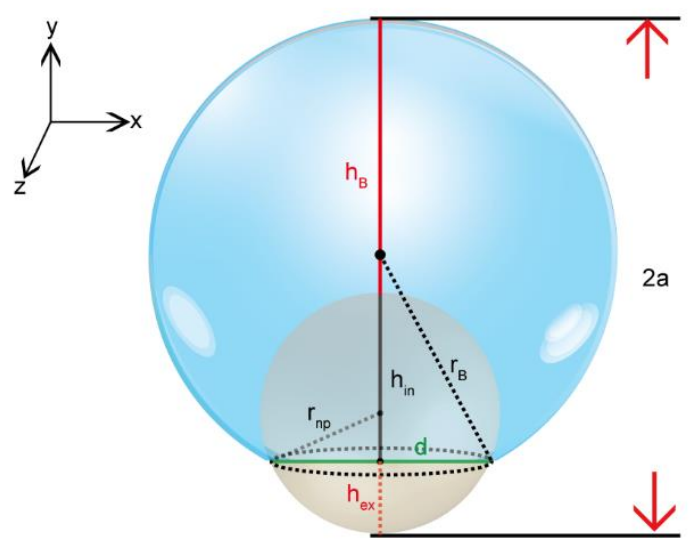

Fig. 4 The computational model geometric structure of a nanobubbleparticle agglomeration.

Having obtained the above results, it was clear that the current traces of single nanobubble-particle agglomerations collision event were correlated directly with the physicochemical properties of oxygen bubble on PtNPs (geometry structure, gas density, etc). In a system with random walks of particle with solvent molecules in bulk solution, the motion velocity of diffusing particle is proportional to diffusion coefficient. Typically, the diffusion coefficient of spherical PtNPs $\left(D_{n p}\right)$ can be calculated by the Stokes-Einstein Equation 1:

$$
D_{n p}=\frac{k_{B} T}{6 \pi \eta r_{n p}}
$$

For a dumbbell-like bubble-particle agglomeration, the diffusion coefficient at parallel $\left(D_{||}\right)$and perpendicular $\left(D_{\perp}\right)$ direction are given by Equation 2, $3^{33}$ :

$$
\begin{gathered}
D_{\|}=\frac{k_{B} T}{8 \pi \eta a} \times \frac{\left(2-p^{2}\right) G(p)-1}{1-p^{2}} \\
D_{\perp}=\frac{k_{B} T}{16 \pi \eta a} \times \frac{\left(2-3 p^{2}\right) G(p)+1}{1-p^{2}}
\end{gathered}
$$

Therefore, the orientation-averaged translational diffusion coefficient of bubble-NP agglomerations $\left(D_{B-P}\right)$ can be expressed as Equation 4:

$$
D_{B-P}=\frac{D_{\|}+2 D_{\perp}}{3}=\frac{k_{B} T}{6 \pi \eta a} G(p)
$$

where $k_{B}$ is Boltzmann constant, $T$ is temperature (298 $\mathrm{K}), \eta$ is the viscosity of solution $(1 \mathrm{mPa} \cdot \mathrm{s})$, and $p$ is the axial ratio. It follows $p=b / a$, where $a$ is the semiaxis along the axis of revolution, $b$ is the equatorial semiaxes. As shown in Fig. 4, $a$ is the half length of bubble-particle agglomerations along y axis $a=\frac{1}{2}\left(h_{B}+2 r_{n p}\right), h_{B}$ is the height of nanobubble and $b$ is the radius of PtNPs. As a result, we derived the correction factors of diffusion coefficient $(\alpha)$ as Equation 5:

$$
\alpha=D_{B-P} / D_{n p}=\frac{r_{n p}}{a} G(p)=\frac{r_{n p}}{a} \log \left(\frac{1+\sqrt{1-p^{2}}}{p}\right) / \sqrt{1-p^{2}}
$$

Since the duration time of current traces is inversely proportional to the diffusion coefficient, $\alpha$ can also be expressed by the ratio of duration times for single PtNPs before and after nanobubble formation as Equation 6:

$$
\alpha=\frac{D_{B-P}}{D_{n p}}=\frac{t_{c=0}}{t_{c=2}}
$$

where $t_{c=2}(=0.23 \mathrm{~ms})$ and $t_{c=0}(=0.15 \mathrm{~ms})$ is the duration time of current traces in $50 \mathrm{mM} \mathrm{HClO}_{4}$ before and after adding $2 \mathrm{mM} \mathrm{H}_{2} \mathrm{O}_{2}$, respectively; thus $\alpha$ is 0.65 in the presence of $2 \mathrm{mM} \mathrm{H}_{2} \mathrm{O}_{2}$. Here, we used the duration time in $2 \mathrm{mM} \mathrm{H}_{2} \mathrm{O}_{2}$ because the oxygen nanobubble no longer grew up as the concentration of $\mathrm{H}_{2} \mathrm{O}_{2}$ further increased to $3 \mathrm{mM}$ and the nanobubble size maintained constant. Accordingly, the height of nanobubble $\left(h_{B}\right)$ was calculated to be $5.26 \mathrm{~nm}$.

Because the current amplitude is proportional to the active catalytic area of PtNP, the unblocked height of external particle cap $\left(\mathrm{h}_{e x}\right)$ by nanobubble can be calculated by Equation 7:

$$
\frac{\mathrm{S}_{c=2}}{S_{c=0}}=\frac{I_{c=2}}{I_{c=0}}=\frac{2 \pi r_{n p} \mathrm{~h}_{e x}}{4 \pi r_{n p^{2}}}
$$

where $\mathrm{S}_{c=0}$ and $\mathrm{S}_{c=2}$ are the superficial area of unblocked PtNPs in $50 \mathrm{mM} \mathrm{HClO}_{4}$ solution without and with $2 \mathrm{mM}$ $\mathrm{H}_{2} \mathrm{O}_{2}$, respectively. Using the corresponding current amplitude $I_{c=0}$ of $47.03 \mathrm{pA}$ and $I_{c=2}$ of $19.88 \mathrm{pA}, \mathrm{h}_{e x}$ was determined to be $1.27 \mathrm{~nm}$. As a result, the blocked height of particle cap $\left(\mathrm{h}_{\text {in }}\right)$ by nanobubble was $1.74 \mathrm{~nm}$ and the basal diameter of nanobubble cap (d) was $2.97 \mathrm{~nm}$.

With the known $h_{B}$ and $\mathrm{d}$, the radius of nanobubble $\left(r_{B}\right)$ was easily obtained by the Pythagorean Theorem $\left(h_{B}+\right.$ $\left.2 r_{n p}-r_{B}-h_{e x}\right)^{2}+\left(\frac{d}{2}\right)^{2}=r_{B}^{2}$. Therefore, the volume of nanobubble $\left(V_{B}\right)$ can be calculated by subtracting the particle volume inside the nanobubble $\left(V_{n p, c a p}\right)$ from the nanobubble cap volume $\left(V_{B, \text { cap }}\right)$ by Equation 8: 
$V_{B}=V_{B, \text { cap }}-V_{n p, \text { cap }}=\frac{\pi\left(h_{B}+h_{i n}\right)^{2}\left(3 r_{B}-h_{B}+h_{i n}\right)}{3}-\frac{\pi h_{\text {in }}^{2}\left(3 r_{n p}-h_{i n}\right)}{3}$

From the theoretically calculated $h_{B}$ and $h_{e x}$, the radius and the volume of $\mathrm{O}_{2}$ nanobubble were estimated to be 3.66 $\mathrm{nm}$ and $195.42 \mathrm{~nm}^{3}$ in $2 \mathrm{mM} \mathrm{H}_{2} \mathrm{O}_{2}$ solution, respectively.

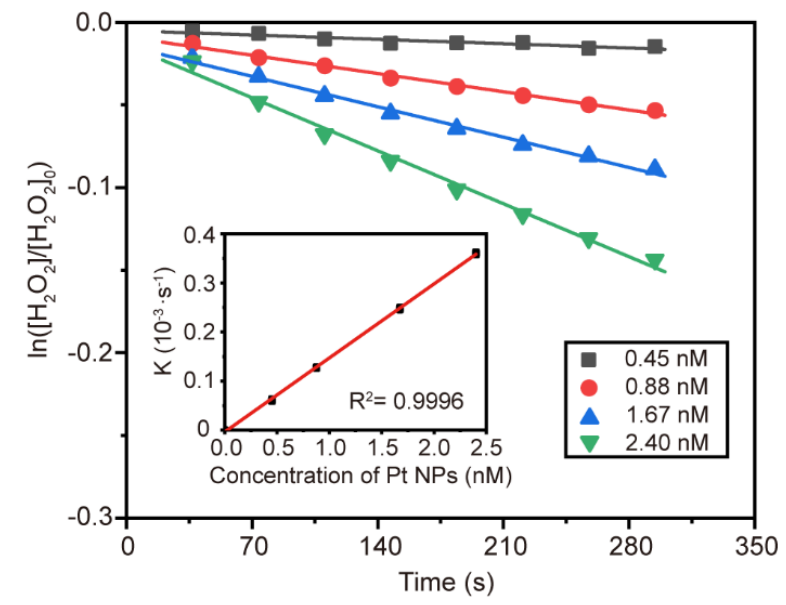

Fig. 5 Decomposition of $\mathrm{H}_{2} \mathrm{O}_{2}$ catalyzed by PtNPs. A plot of $\ln \left(\left[\mathrm{H}_{2} \mathrm{O}_{2}\right] /\left[\mathrm{H}_{2} \mathrm{O}_{2}\right]_{0}\right)$ against decomposition time of $\mathrm{H}_{2} \mathrm{O}_{2}$ at various concentrations of $3 \mathrm{~nm}$ PtNPs at $25^{\circ} \mathrm{C}$. Inset: The measured pseudo first order rate constants as a function of the concentration of PtNPs.

To provide a quantitative understanding of nanobubble, we further investigated the chemical catalytic decomposition of $\mathrm{H}_{2} \mathrm{O}_{2}$ in a suspension of PtNPs. As shown in Supplementary Fig. 5, the calibration curve with a good correlation coefficient $\left(\mathrm{R}^{2}=0.99987\right)$ indicated that the absorbance peak of $\mathrm{H}_{2} \mathrm{O}_{2}$ at $240 \mathrm{~nm}$ could be used to determine its concentration by converting absorbance in this study. We used a UV-vis spectrometer to monitor the absorbance at $240 \mathrm{~nm}$ of $2 \mathrm{mM} \mathrm{H} \mathrm{H}_{2}$ and $50 \mathrm{mM} \mathrm{HClO}_{4}$ solution initially containing $0.45 \mathrm{nM}, 0.88 \mathrm{nM}, 1.67 \mathrm{nM}$ and $2.4 \mathrm{nM}$ PtNPs, respectively, over a period of ca. $40 \mathrm{~s}$. The decomposition rate, $k$, was obtained by a pseudo first order calibration method and showed a linear dependence on concentration of PtNPs (Fig. 5). Using the slope of the plot, the $k_{\text {decomp }}$ at $100 \mathrm{pM}$ PtNPs solution was determined to be $1.14 \times 10^{-5} \mathrm{~s}^{-1}$ in a manner consistent with the previously obtained results ${ }^{34}$. Thus, a pseudo-first order rate constant on a per PtNP basis can be expressed by Equation 9:

$$
k_{N P}=k_{\text {decomp }} / N_{A} C_{N P}
$$

where $N_{A}$ is Avocadoro Constant and $C_{N P}$ is the concentration of PtNPs. And the calculated $K_{\mathrm{NP}, \mathrm{H}_{2} \mathrm{O}_{2}}$ was found to be $2.44 \times 10^{-21} \mathrm{~m}^{3} \cdot \mathrm{s}^{-1}$ for a diameter of $3.0 \mathrm{~nm}$ PtNP. Next, we further calculated the number of the oxygen molecule in decomposition process per PtNP by Equation 10:

$$
n_{\mathrm{O}_{2}}=\frac{1}{2} \int_{0}^{t_{s}} K_{\mathrm{NP}, \mathrm{H}_{2} \mathrm{O}_{2}} C_{0} e^{-k_{\text {decomp }} t} d t
$$

where $C_{0}(=2 \mathrm{mM})$ is the initial concentration of $\mathrm{H}_{2} \mathrm{O}_{2}$ around the PtNPs and $t_{s}(=300 \mathrm{~s})$ is the fomation time of $\mathrm{O}_{2}$ nanobubble on PtNPs (Supplementary Fig. 6). Based on the calculated $n_{\mathrm{O}_{2}}$, we estimated the density of $\mathrm{O}_{2}$ gas inside a nanobubble, $\rho_{\mathrm{O}_{2}}$, by Equation 11 :

$$
\rho_{O_{2}}=\frac{n_{O_{2}} M_{O_{2}}}{V_{B}}
$$

where $M_{\mathrm{O}_{2}}$ is the molecular weight of $\mathrm{O}_{2}$. Equation 11 allowed the calculated $\mathrm{O}_{2}$ gas density in a single nanobubble was $9286 \mathrm{~kg} / \mathrm{m}^{3}$. In this work, the oxygen density inside was 3 orders of magnitude higher than that in atmospheric pressure (the density of oxygen gas is $1.30 \mathrm{~kg} / \mathrm{m}^{3}$ at 1 bar and $298 \mathrm{~K}$ ), revealing these nanosized bubbles were found in a highly oversaturated state.

Considering nanoscale bubble with highly curved interfaces, the gas density inside the surface nanobubble can be described by well-known Young-Laplace Equation $12^{35}$ :

$$
\frac{\rho}{\rho_{0}}=\frac{2 \gamma}{r P_{0}}+1
$$

where $\rho / \rho_{0}$ is the normalized density, $\gamma$ is the surface tension at a curved liquid-gas interface, $r$ is the bubble's curvature radius of nanobubble and $\rho_{0}$ is the gas density at ambient pressure. For a surface nanobubble with a curvature radius of $3.66 \mathrm{~nm}, \gamma$ is $72 \mathrm{mN} / \mathrm{m}$, and $P_{0}$ is $101 \mathrm{kPa}$, and then the density $\rho$ of gas molecules inside nanobubble is about $507 \mathrm{~kg} / \mathrm{m}^{3}$, which is at least 1 order of magnitude less than our results from single NP electrochemical measurements. This difference implies that the validity in using the macroscopic surface tension for describing curved interfaces with radius smaller than tens of nanometers is not applicable. The high density of the gas molecules confined inside a nanobubble may ascribe to the low diffusion of oxygen molecules from the nanobubble to the surrounding solution.

\section{Discussion}

In summary, we have demonstrated the possibility to monitor the nanobubble-confined electrochemical behaviors of single free-diffusing PtNPs in real time. Based on highresolution electrochemical measurements and theoretical calcution, our results can also be used for quantifying the physicochemical properties of nanobubble (size and high gas density) on PtNPs surface. A astonishing high density of oxygen nanobubble was obtained from individual collision events compared with the ideal gas in atmospheric pressure, which may originate from the gas inside nanobubbles could maintain a dense state instead of ideal gas state. This work provides new insights to unveil the scientific mysteries of nanobubbles, for example, long-term stability of surface nanobubbles.

\section{Methods}

\section{Materials.}

The chemicals were used as received from manufacturers. sodium $\left(\mathrm{NaBH}_{4}\right)$, perchloric acid $\left(\mathrm{HClO}_{4}, 70 \%\right)$, chloroplatinic acid hexahydrate $\left(\mathrm{H}_{2} \mathrm{PtCl}_{6} \cdot 6 \mathrm{H}_{2} \mathrm{O}\right)$, sodium perchlorate monohydrate $\left(\mathrm{NaClO}_{4}\right)$, hydrogen peroxide 
$\left(\mathrm{H}_{2} \mathrm{O}_{2}, 30 \mathrm{wt} \%\right)$ were purchased from Sigma-Aldrinch. Poly(ethylene glycol) (PEG) was purchased from Aladdin Chemical Company (Shanghai, China). Tributyl phosphate was purchased from Meryer Chemical Company (Shanghai, China). Carbon fiber wires (7 $\mu \mathrm{m}$ diameter, Good fellow, Devon, PA), glass capillary (Sutter Instrument, Novato, CA), epoxy adhesive (Loctite, USA) and silver-epoxy adhesive (Epoxy Technology, USA) were used to fabricate the C UME. Diamond lapping films $(1.0 \mu \mathrm{m}, 0.3 \mu \mathrm{m}$ and $0.1 \mu \mathrm{m})$ for polishing UME was purchased from TED Pella, Inc. Pt counter electrode for electrochemical experiment were purchased from Shanghai Chenhua Co., Ltd., China. The water used for all experimental solutions was purified by water purification system, Millipore UHQ II system (Elga), with a resistivity of $18.2 \mathrm{M} \Omega \cdot \mathrm{cm}$ at $298 \mathrm{~K}$.

\section{Electrochemical measurement.}

A carbon fiber UME (C UME) with radius of $3.5 \mu \mathrm{m}$ was applied at a constant potential $-500 \mathrm{mV}$ vs. $\mathrm{Ag} / \mathrm{AgCl}$. The current response was recorded with an Axopatch 200B amplifier (Axon Instruments). The amplifier's internal lowpass Bessel filter was set as $5 \mathrm{kHz}$. The current signal was sampled at $100 \mathrm{kHz}$ using a 1550B digitizer (Axon Instruments). Amperometric data were recorded using Axoscope 10.0 software (Molecule Devices) and analyzed with Clampfit 10.6 (Molecular Devices). All electrochemical experiments were performed in a home-built, grounded faraday cage. $\mathrm{An} \mathrm{Ag} / \mathrm{AgCl}$ wire quasi-reference electrode was used for all electrochemical experiments.

\section{Preparation of PtNPs.}

PtNPs were synthesized according to a previous report ${ }^{36}$. Briefly, $3 \mathrm{~mL}$ of $50 \mathrm{mM}$ aqueous sodium citrate solution was added to $60 \mathrm{~mL}$ of $2 \mathrm{mM}$ aqueous $\mathrm{H}_{2} \mathrm{PtCl}_{6}$ solution. Under vigorous stirring, $7 \mathrm{~mL}$ of $120 \mathrm{mM} \mathrm{NaBH}_{4}$ solution was added dropwise to obtain a Pt hydrosol where citrate ions served as the stabilizer. Then keeping the solution under stirring for $40 \mathrm{~min}$, the monodisperse PtNPs solution with black color was obtained.

\section{Characterization of PtNPs.}

High-resolution Transmission electron microscopy (TEM) images was recorded on a JEM 2100 TEM with an accelerating voltage of $300 \mathrm{kV}$. TEM examination showed that the as-prepared citrate capped PtNPs had a narrow size distribution with an average diameter of $3.0 \pm 0.1 \mathrm{~nm}$ (Supplementary Fig. 1).

\section{Data availability}

The data that support the findings of this study are available from the corresponding authors upon reasonable request.

\section{Reference}

1. Lohse, D. \& Zhang, X. Surface nanobubbles and nanodroplets. Rev. Mod. Phys. 87, 981-1035 (2015).

2. Parker, J. L. \& Claesson, P. M. Bubbles, cavities, and the long-ranged attraction between hydrophobic surfaces. J. Phys. Chem. 98, 8468-8480 (1994).

3. Ding, S. et al. New insights into the role of surface nanobubbles in bubble-particle detachment. Langmuir 36, 4339-4346 (2020).
4. Ren, H., German, S. R., Edwards, M. A., Chen, Q. \& White, H. S. Electrochemical generation of individual $\mathrm{O}_{2}$ nanobubbles via $\mathrm{H}_{2} \mathrm{O}_{2}$ oxidation. J. Phys. Chem. Lett. 8, 2450-2454 (2017).

5. Zhang, X. H., Maeda, N. \& Craig, V. S. J. Physical properties of nanobubbles on hydrophobic surfaces in water and aqueous solutions. Langmuir 22, 5025-5035 (2006).

6. Song, B., Chen, K., Schmittel, M. \& Schönherr, H. AFM study of surface nanobubbles on binary selfassembled monolayers on ultraflat gold with identical macroscopic static water contact angles and different terminal functional groups. Langmuir 32, 1117211178 (2016).

7. Liu, Y.\& Dillon, S. J. In situ observation of electrolytic $\mathrm{H}_{2}$ evolution adjacent to gold cathodes. Chem. Commun. 50, 1761-1763 (2014).

8. Shin, D. et al. Growth dynamics and gas transport mechanism of nanobubbles in graphene liquid cells. Nat. Commun. 6, 1-6 (2015).

9. Hao, R., Fan, Y., Howard, M. D., Vaughan, J. C. \& Zhang, B. Imaging nanobubble nucleation and hydrogen spillover during electrocatalytic water splitting. Proc. Natl. Acad. Sci. U. S. A. 115, 58786588 (2018).

10. Li, S. et al. Nanobubbles: An effective way to study gas-generating catalysis on a single nanoparticle. J. Am. Chem. Soc. 139, 14277-14284 (2017).

11. Chen, Q., Wiedenroth, H. S., German, S. R. \& White, H. S. Electrochemical nucleation of stable $\mathrm{N}_{2}$ nanobubbles at Pt nanoelectrodes. J. Am. Chem. Soc. 137, 12064-12069 (2015).

12. Liu, Y., Edwards, M. A., German, S. R., Chen, Q. \& White, H. S. The dynamic steady state of an electrochemically generated nanobubble. Langmuir 33, 1845-1853 (2017).

13. Soto, Á. M. et al. The nucleation rate of single $\mathrm{O}_{2}$ nanobubbles at Pt nanoelectrodes. Langmuir 34, 73097318 (2018).

14. Dockar, D., Borg, M. K. \& Reese, J. M. Mechanical stability of surface nanobubbles. Langmuir 35, 93259333 (2019).

15. Borkent, B. M., Dammer, S. M., Schönherr, H., Vancso, G. J. \& Lohse, D. Superstability of surface nanobubbles bram. Phys. Rev. Lett. 98, 18-21 (2007).

16. Nirmalkar, N., Pacek, A. W. \& Barigou, M. On the existence and stability of bulk nanobubbles. Langmuir 34, 10964-10973 (2018).

17. Zhang, X. H., Khan, A. \& Ducker, W. A. A nanoscale gas state. Phys. Rev. Lett. 98, 136101-136104 (2007).

18. Maheshwari, S., Van Der Hoef, M., Zhang, X. \& Lohse, D. Stability of surface nanobubbles: A molecular dynamics study. Langmuir 32, 11116-11122 (2016).

19. Zhang, X., Chan, D. Y. C., Wang, D. \& Maeda, N. Stability of interfacial nanobubbles. Langmuir 29, 1017-1023 (2013).

20. Ljunggren, S. \& Eriksson, J. C. The lifetime of a colloid-sized gas bubble in water and the cause of the hydrophobic attraction. Colloids Surf. A. 130, 151-155 (1997). 
21. German, S. R. et al. Interfacial nanobubbles are leaky: Permeability of the gas/water interface. ACS Nano 8, 6193-6201. (2014).

22. Chen, J. et al. Measuring the activation energy barrier for the nucleation of single nanosized vapor bubbles. Proc. Natl. Acad. Sci. U. S. A. 116, 12678-12683 (2019).

23. Zhang, L. et al. Imaging interfacial micro- and nanobubbles by scanning transmission soft X-ray microscopy. J. Synchrotron Radiat. 20, 413-418 (2013).

24. Ma, W., Ma, H., Peng, Y. Y., Tian, H. \& Long, Y. T. An ultrasensitive photoelectrochemical platform for quantifying photoinduced electron-transfer properties of a single entity. Nat. Protoc. 14, 2672-2690 (2019).

25. Sun, Z., Hafez, M. E., Ma, W. \& Long, Y. T. Recent advances in nanocollision electrochemistry. Sci. China Chem. 62, 1588-1600 (2019).

26. Sepunaru, L., Sokolov, S. V., Holter, J., Young, N. P. \& Compton, R. G. Electrochemical red blood cell counting: One at a time. Angew. Chem. Int. Ed. 55, 9768-9771 (2016).

27. Dick, J. E., Hilterbrand, A. T., Boika, A., Upton, J. W. \& Bard, A. J. Electrochemical detection of a single cytomegalovirus at an ultramicroelectrode and its antibody anchoring. Proc. Natl. Acad. Sci. U. S. A. 112, 5303-5308 (2015).

28. Dunevall, J. et al. Characterizing the catecholamine content of single mammalian vesicles by collision-adsorption events at an electrode. J. Am. Chem. Soc. 137, 4344-4346 (2015).

29. Dick, J. E., Renault, C. \& Bard, A. J. Observation of single-protein and DNA macromolecule collisions on ultramicroelectrodes. J. Am. Chem. Soc. 137, 83768379 (2015).

30. Ma, W. et al. Tracking motion trajectories of individual nanoparticles using time-resolved current traces. Chem. Sci. 8, 1854-1861 (2017).

31. Zhang, M. \& Seddon, J. R. T. Nanobubble-nanoparticle interactions in bulk solutions. Langmuir 32, 11280-11286 (2016).

32. Chen, Q., Luo, L., Faraji, H., Feldberg, S. W. \& White, H. S. Electrochemical measurements of single $\mathrm{H}_{2}$ nanobubble nucleation and stability at $\mathrm{Pt}$ nanoelectrodes. J. Phys. Chem. Lett. 5, 3539-3544 (2014).

33. Hoffmann, M., Wagner, C. S., Harnau, L. \& Wittemann, A. 3D brownian diffusion of submicronsized particle clusters. ACS Nano 3, 3326-3334 (2009).

34. Yu, W., Batchelor-Mcauley, C., Chang, X., Young, N. P. \& Compton, R. G. Porosity controls the catalytic activity of platinum nanoparticles. Phys. Chem. Chem. Phys. 21, 20415-20421 (2019).

35. Zhou, L. et al. Ultrahigh density of gas molecules confined in surface nanobubbles in ambient water. $J$. Am. Chem. Soc. 142, 5583-5593 (2020).

36. Yang, J., Lee, J. Y. \& Too, H. P. Size effect in thiol and amine binding to small Pt nanoparticles. Anal. Chim. Acta, 571, 206-210 (2006).

\section{Acknowledgements}

This research was supported by Major Research Project (92061108), National Natural Science Foundation of China (21775043), Shanghai Municipal Natural Science Fund (19ZR1472100), Shanghai Pujiang Program (2019PJD010) and Xiamen University Opening Project of PCOSS (201901).

\section{Author contributions}

W.M. conceived and managed the project. W.M. designed the experiments. Z.-H.S. performed the experiments, analyzed the data and wrote the manuscript. Z.-H.G. performed the experiment and co-wrote the manuscript. W.M. analyzed the data, wrote the manuscript and organized the experimental and simulated results. All authors discussed the results and commented on the manuscript.

\section{Competing interests}

The authors declare no competing interest.

\section{Additional information}

Correspondence and requests for materials should be addressed to W.M. 


\section{Supplementary Files}

This is a list of supplementary files associated with this preprint. Click to download.

- Supportinglnformation.pdf 